\title{
Humidity interaction of lichens under astrobiological aspects: the impact of UVC exposure on their water retention properties
}

\author{
J. Jänchen', J. Meeßen ${ }^{2}$, T.H. Herzog', M. Feist ${ }^{3}$, R. de la Torre ${ }^{4}$ and J.-P.P. deVera ${ }^{5}$ \\ ${ }^{1}$ Technical University of Applied Sciences Wildau, Volmerstr. 13, 12489 Berlin, Germany \\ e-mail: jochen.jaenchen@th-wildau.de \\ ${ }^{2}$ Institute of Botany, Heinrich-Heine-University Düsseldorf, Universitätsstr. 1, 40225 Düsseldorf, Germany \\ ${ }^{3}$ Institute of Chemistry, Humboldt University Berlin, Brook-Taylor-Str. 2, 12489 Berlin, Germany \\ ${ }^{4}$ Department of Earth Observation, Spanish Institute for Aerospace Technology (INTA), Ctra. Ajalvir km 4.5, \\ 28850Torrejónde Ardoz, Spain \\ ${ }_{5}^{5}$ Institute of Planetary Research, German Aerospace Center (DLR), Rutherfordstr. 2, 12489 Berlin, Germany
}

\begin{abstract}
We quantitatively studied the hydration and dehydration behaviour of the three astrobiological model lichens Xanthoria elegans, Buellia frigida and Circinaria gyrosa by thermoanalysis and gravimetric isotherm measurements under close-to-Martian environmental conditions in terms of low temperature and low pressure. Additionally, the impact of UVC exposure on the isolated symbionts of $B$. frigida and $X$. elegans was studied by thermoanalysis and mass spectrometry as well as by gravimetric isotherm measurements. The thermal analysis revealed whewellite as a component of C. gyrosa which was not found in B. frigida and X. elegans. Neither the water retention nor the thermal behaviour of symbionts changed when irradiated with UVC under dry conditions. On the other hand, UVC irradiation of the wet mycobiont of $B$. frigida had a distinct impact on the hydration/dehydration ability which was not observed for the mycobiont of $X$. elegans. Possibly the melanin of $B$. frigida's mycobiont, that is not present in X. elegans, or a specifically damaged acetamido group of the chitin of $B$. frigida may be the sources of additional UVCinduced sorption sites for water associated with the UVC exposure.
\end{abstract}

Received 11 December 2014, accepted 8 January 2015

Key words: lichen, Mars, thermoanalysis, UVC irradiation, water sorption isotherms

\section{Introduction}

In the field of planetary sciences new observations and results of recent and on-going missions continuously fuel the debate on the habitability of Mars, especially regarding measurements of the planet's surface radiation environment (Hassler et al. 2014), its detailed mineralogy (Williams et al. 2013; Grotzinger et al. 2014), new announcements of MSL findings and their implications for the surface conditions at Gale crater (Ming et al. 2014; Vaniman et al. 2014) as well as the occurrence of water in the equatorial regions of Mars (Feldman et al. 2004; Bibring et al. 2005; Poulet et al. 2005; McEwen et al. 2012).

Based on the observation that all terrestrial life unquestionably depends on water, the search for at least temporarily available sources of water is one of the main topics in astrobiological research related to Mars. A fact is also mirrored by NASA's 'follow the water' strategy for Mars exploration (Hubbard et al. 2002). Mars bears an estimated near surface water reservoir of about $5000000 \mathrm{~km}^{3}$ mostly bound in the polar ice caps and ice-rich subsurface layers (Christensen 2006). Below $60^{\circ}$ of latitude it is locally found in concentrations of up to $18 \%$, polewards of $70^{\circ}$ of latitude it mostly exceeds $25 \%$ and approaches $100 \%$ at the poles itself (Feldman et al. 2004). Nonetheless, summarizing the increasing knowledge of water abundance and its physical conditions, Mars' surface is classified as a hyper-arid cold desert (Marchant \& Head 2007).

Due to Mars' low surface temperatures water is predominantly frozen (Christensen 2006). At the Viking landing sites temperatures range from $-17^{\circ}$ to $-107^{\circ} \mathrm{C}$ at $1.5 \mathrm{~m}$ above the surface; in winter they drop to minima of about $-143^{\circ} \mathrm{C}$ at the polar caps but frequently surpass $0^{\circ} \mathrm{C}$ during summer daytime in subtropical to equatorial regions with soil maxima of up to $27^{\circ} \mathrm{C}$ (Hess et al. 1977; Tillman 1988; Murphy et al. 1990). Although the amount of water vapour in Mars' atmosphere is small by terrestrial standards, the relative humidity (RH) can be quite high (Davies 1979) depending on daytime, season, latitude and orographic factors (Briggs et al. 1977). Viking revealed the occasional presence of morning fogs and Viking Orbiter 2 showed large amounts of water vapour over the north polar remnant cap during summer (Farmer et al. 1977) while the infrared thermal mapper of Viking Orbiter 2 implied that the atmosphere is near or at saturation at some seasons (Kieffer et al. 1977).

On the other hand, liquid surface water is considered to be restricted to narrow, temporary and rare conditions. Besides 
it is not yet understood (seasonal) outflow events from subsurface groundwater reservoirs into gullies (Malin et al. 2006). Möhlmann (2010) depicted three possible conditions for liquid water: undercooled liquid interfacial (ULI) water, undercooled liquid water in cryo-brines and liquid bulk water in the subsurface of ice areas. ULI water that occur on soil grains is discussed as reversibly bound and partially unfrozen films of adsorption water with a thickness of several micrometres only but with an water activity $\left(a_{\mathrm{w}}\right)$ above the assumed minimum for terrestrial life of 0.6 (Jakosky et al. 2003; Möhlmann 2004, 2008). Besides sulphatic salts, cryo-brines might be formed by hygroscopic minerals as hydrogen peroxide (Houtkooper \& Schulze-Makuch 2009) and perchlorates (Houtkooper \& Schulze-Makuch 2010) of which the latter was recently detected on Mars by the Phoenix lander (Hecht et al. 2009; Rennó et al. 2009; Smith et al. 2009).

Such utmost scarcity of liquid water, even on a rather Earth-like celestial body like Mars, raises the interest of astrobiologists in extremophile and extremotolerant organisms that resist highly restricted and infrequent water availability in their natural habitat. These organisms are found in arctic, antarctic, alpine and desert environments where intense desiccation stress is accompanied by high insolation, high levels of UVR and extreme temperatures. Such habitats are considered to be as close as possible to Martian conditions and therefore investigated as Mars Analogue Sites. For example, the Andean Atacama Desert (McKay et al. 2003) and the dry valley cold deserts in continental Antarctica (Marchant \& Head 2007; Harańczyk et al. 2008; Sun et al. 2010) are among the most Mars-like terrestrial habitats on Earth.

Lichens are organisms that are able to tolerate severe environmental conditions (Kappen 1973, 1988, 1993) and successfully colonize such extreme polar, alpine and arid habitats (Lange 1992). Therefore, they represent useful model systems in astrobiological research (Sancho et al. 2007; de Vera et al. 2010). Lichens are symbiotic associations constituted of a heterotrophic fungus (mycobiont) and a photoautotrophic partner (photobiont) that form a unique thallus structure with emergent morphological and physiological adaptations towards the harsh conditions at the natural habitat (Kappen 1988; Lange et al. 1999, 2001). Among these adaptations, three adaptive traits are chiefly relevant in constituting extremotolerance and protecting both symbionts: a number of morphological and anatomical features (Meeßen et al. 2013), a diverse set of secondary lichen compounds (SLCs, Meeßen et al. 2014) and, most important in the present context, anhydrobiosis. It allows lichens to tolerate intense desiccation by passing into an ametabolic state (Kranner et al. 2005). Moreover, anhydrobiosis protects lichens against stressors that come along with drought, including severe temperatures and high levels of light or ultraviolet radiation (UVR, Nybakken et al. 2004). In nature, the availability of water is often correlated to more moderate climatic conditions and rehydration by liquid water or high air humidity (>80\%, Sigfridsson \& Oquist 1980; Lange et al. 1986) which leads to metabolic re-activation. Regarding astrobiology, the protective effect of anhydrobiosis is stressed by recent studies on lichen UVC-resistance in anhydrobiosis, and when physiologically active (Sánchez et al. 2014).
In the context of Martian habitability, the adaptation of extremophile and extremotolerant organisms towards severe and lasting desiccation is of peculiar interest. The detailed analysis and understanding of water uptake and retention kinetics of organisms is beneficial to understand the constraints of Martian habitability. Thus, three experimental set-ups applied three parameters that are clearly linked to Martian environmental conditions: (i) irradiation with UVC, which is an environmental stressor at Martian ground level but not on Earth, (ii) a set of three temperatures that represent moderate Martian conditions of up to $-17^{\circ} \mathrm{C}$ at the Viking landing sites and up to $27^{\circ} \mathrm{C}$ in low latitudes (Hess et al. 1977; Tillman 1988; Murphy et al. 1990), (iii) a RH that can occasionally become saturated and produce morning fogs, although the amount of atmospheric water vapour is low compared to Earth (Briggs et al. 1977; Farmer et al. 1977; Kieffer et al. 1977; Davies 1979). Furthermore, it may also contribute to the understanding of the resistance of terrestrial organisms towards simulated space and Martian condition (de Vera et al. 2003, 2004a, b, 2008, 2010, 2013; Sánchez et al. 2012, 2014) in previous (de la Torre et al. 2007, 2010; Sancho et al. 2007; Raggio et al. 2011; Onofri et al. 2012; Scalzi et al. 2012; Brandt et al. 2014) and current space exposure experiments (i.e. BIOMEX, Biology and Mars Experiment at the EXPOSE-R2 facility on board the ISS, launched in July 2014, start of $\sim 12$ month-exposure in October 2014). An important issue to be tackled in this research is the interaction of moisture of the planet's atmosphere with hypothetical organisms of the planet's surface because of the essential role of water for life. Based in previous studies (Jänchen et al. 2013, 2014a, b) we examined the water vapour interaction and water-bearing properties of the three astrobiological model lichens Buellia frigida, Xanthoria elegans and Circinaria gyrosa. The experiments were partially conducted after irradiation with UVC to simulate an environmental parameter typically for Mars but not found on Earth. Our aim is to contribute to an improved knowledge of extremotolerant organisms under astrobiological aspects within the frame of BIOMEX with an emphasis on the effects of UVC irradiation on water retention properties. The results may also support data evaluation of future Mars simulation studies or in-situ missions such as ExoMars.

\section{Experimental}

\section{Biological samples}

All three lichens, B. frigida Darb. (1910), C. gyrosa Sohrabi (2012) and $X$. elegans (Link) Th. Fr. (1860), represent symbiotic and eukaryotic associations formed by an ascomycete fungus (Lecanoromycetes) and a green alga (Trebouxiophyceae). While $B$. frigida is an extremophile Antarctic endemite (collected 2010 at Gerlach Inlet, Gondwanaland, Antarctica, $74^{\circ} 38^{\prime} \mathrm{S}, 164^{\circ} 13^{\prime} \mathrm{E}$ ) and C. gyrosa originates from arid highland areas of central Spain (collected 2010 in Zaorejas, Spain, $1260 \mathrm{~m}$ a.s.1.), X. elegans is found in exposed alpine and circumpolar habitats (collected 2008 at Col du Sanetsch, Valais, Switzerland, $2140 \mathrm{~m}$ a.s.1.). All three species are well adapted to drought, high levels of insolation 
and UVR experienced at their natural habitats but also to extremes of cold or heat, respectively (Sancho et al. 2000; Øvstedal \& Smith 2001). C. gyrosa was found to survive real and simulated space exposure (de la Torre et al. 2007, 2010; Raggio et al. 2011; Onofri et al. 2012) without forming relevant amounts of UVR-shielding SLCs but pronounced amounts of intermedullary calciumoxalate monohydrate crystals (Böttger et al. 2013). In contrast, B. frigida and X. elegans form substantial amounts of melanin and parietin as dominant SLCs in their respective cortices. $X$. elegans was also shown to survive real and simulated space exposure (de Vera et al. 2003, 2004a, b) as well as to photosynthesize under simulated Martian conditions (de Vera et al. 2008, 2010; de la Torre et al. 2010). B. frigida and C. gyrosa are part of the current BIOMEX space exposure mission outside the ISS. Detailed information on these lichens' morphological-anatomical adaptations towards extreme environmental conditions and their SLC inventory can be found elsewhere (Meeßen et al. 2013, 2014). Besides the thalli of all three species, we investigated the isolated mycobiont of $B$. frigida and $X$. elegans, the photobiont of $B$. frigida as well as pure whewellite (calciumoxalate monohydrate) and chitin which is one of the main dry weight components of lichen fungi.

\section{UVC sample treatment}

A set of samples consisting of isolated mycobionts of $B$. frigida and $X$. elegans as well as of the isolated photobiont of $B$. frigida was exposed to UVC at $\lambda=254 \mathrm{~nm}$ under dry (D) and wet (W) conditions. The irradiation was performed in an air circulation cabinet (Mühlenkamp $\mathrm{GmbH}$ ) equipped with a HNS 30W G13 G30T8/OF UVC lamp (Puritec ${ }^{\mathbb{R}}$, Osram, >93\% emission at $254 \mathrm{~nm}$ ). After $20 \mathrm{~min}$ pre-run, the $\mathrm{UVC}_{254 \mathrm{~nm}}$ irradiance was adjusted to $480 \mu \mathrm{Wcm}^{-2}$ (measured with an UVP UVX dosimeter, sensor 25 at $254 \mathrm{~nm}$ ). The exposure times were $0 \mathrm{~h}, 10 \mathrm{~h}$ (accumulated dose of $17280 \mathrm{~J} \mathrm{~cm}^{-2}$ ) and $50 \mathrm{~h}$ (accumulated dose of $86400 \mathrm{~J} \mathrm{~cm}^{-2}$ ). The corresponding sample codes are D0, D10, D50 for dry treatment and W0, W10, W50 for exposure of wet samples, respectively. After exposure the samples were dried over silica gel assuring comparably low initial water content and safe storage/transport. Prior to thermogravimetry (TG) the samples were preconditioned as described below. The isotherm measurements were started with the 'silica gel dry' samples as delivered.

\section{Physico-chemical methods}

The dehydration properties and the thermal decomposition (TG, differential thermogravimetry, DTG and differential thermoanalysis, DTA) were measured on a Netzsch STA 409 apparatus with a heating rate of $10 \mathrm{~K} \mathrm{~min}^{-1}$ up to $1273 \mathrm{Kusing}$ $\mathrm{Al}_{2} \mathrm{O}_{3}$ crucibles. The purge gas flow $\left(\mathrm{N}_{2}\right.$, Air Liquide, 5.0) was $70 \mathrm{ml} \mathrm{min}{ }^{-1}$. Prior to the TG experiments the lichens and their symbionts were preconditioned at controlled atmosphere for 6 days over saturated ammonium chloride solution in an evacuated desiccator at $p / p_{\mathrm{s}}=0.79$, equal to $\mathrm{RH}$ of $\mathrm{RH}=79 \%$.

Supplementary to conventional (TG, DTG, DTA) thermoanalytical (TA) measurements, simultaneously coupled mass spectrometry (TA-MS) investigations were performed. A
Netzsch thermoanalyzer STA 409 C Skimmer ${ }^{\mathbb{R}}$ system, equipped with a Balzers QMG 421, was used to record the TA curves together with the ionic current (IC) curves in the multiple ion detection (MID) mode (Emmerich \& Post 1997; Kaisersberger \& Post 1997). A DTA-TG sample carrier system with platinum crucibles (beaker, $0.8 \mathrm{ml}$ ) and Pt/PtRh10 thermocouples was used. Samples of 13-20 mg each were measured against an empty reference crucible. A constant purge gas flow of $70 \mathrm{ml} \mathrm{min}{ }^{-1} \mathrm{~N}_{2}$ (Messer-Griesheim, 5.0) and a constant heating rate of $10 \mathrm{~K} \mathrm{~min}^{-1}$ were applied. The raw data were evaluated with the manufacturer's software Proteus ${ }^{\circledR}$ (v. 4.3) and QuadStar 422 (v. 6.02) without further data treatment, e.g. smoothing. The initial $\left(T_{\mathrm{i}}\right)$, extrapolated onset $\left(T_{\mathrm{on}}^{\mathrm{ex}}\right)$, and peak temperatures $\left(T_{\mathrm{p}}\right)$ were determined following standard recommendations (Hill 1991).

The base line shift of the IC signals for practically all mass numbers at higher temperatures is the characteristic of the Skimmer ${ }^{\circledR}$ system (Hanss et al. 2003) where the gas sampling system and the sample holder have the same temperatures to avoid condensation phenomena. Consequently, the MS signal becomes temperature-dependent as the lower gas viscosity affects an increasing gas flow through the sampling orifices of the coupled TA-MS cell, thus leading to an increasing IC intensity. A real substance release from the sample can be deduced only from a distinctly expressed additional IC maximum on the constantly increasing baseline which was not the case here. The mass number assignment is abbreviated in the form of $\mathrm{m} 18$ representing $\mathrm{m} / \mathrm{z}=18$. The hydration state of the sample for the present TA-MS study was 'room-dry' ( $\mathrm{RH}<0.79)$ different to the TG experiments described above.

The sorption/desorption (hydration/dehydration) isotherms were measured gravimetrically from 255 to $293 \mathrm{~K}$ with a McBain-Bakr quartz spring balance (McBain \& Bakr 1926) equipped with MKS Baratron pressure sensors covering a range of $10^{-5}-10^{3} \mathrm{mbar}$. This allowed measurements of the isotherms in the range $P=0.01-P=20$ mbar water vapour pressure. The dilation/contraction of the spring was followed with a cathetometer. The sensitivity of the quartz spring was $4 \mathrm{~mm} \mathrm{mg}^{-1}$ and the resolution of the cathetometer $0.01 \mathrm{~mm}$. So the resolution for the water uptake (using $100 \mathrm{mg}$ sample) was $0.0004 \mathrm{~g} \mathrm{~g}^{-1}$. Prior to each sorption experiment, about $100 \mathrm{mg}$ sample was degassed over night at $293 \mathrm{~K}$ and $P<10^{-5}$ mbar. This state is regarded as 'vacuum dry'.

\section{Results and discussion}

\section{Thermogravimetry}

The TA curves give a comparably easy access to mass loss data and thermal information as a function of temperature including the release of sorbed water. Figure 1 provides records of the (reversibly) physisorbed water (mass loss up to ca. $450 \mathrm{~K}$ ) as well as the thermal decomposition up to $900 \mathrm{~K}$ for all three lichens investigated. Due to the different mass losses up to $450 \mathrm{~K}$ it can be concluded that $C$. gyrosa from the dry warm environment took less water (at $\mathrm{RH}=79 \%$ ) than B. frigida (and less pronounced for $X$. elegans) which are adapted to the dry cold Alpine or Antarctic habitats. Moreover, the 


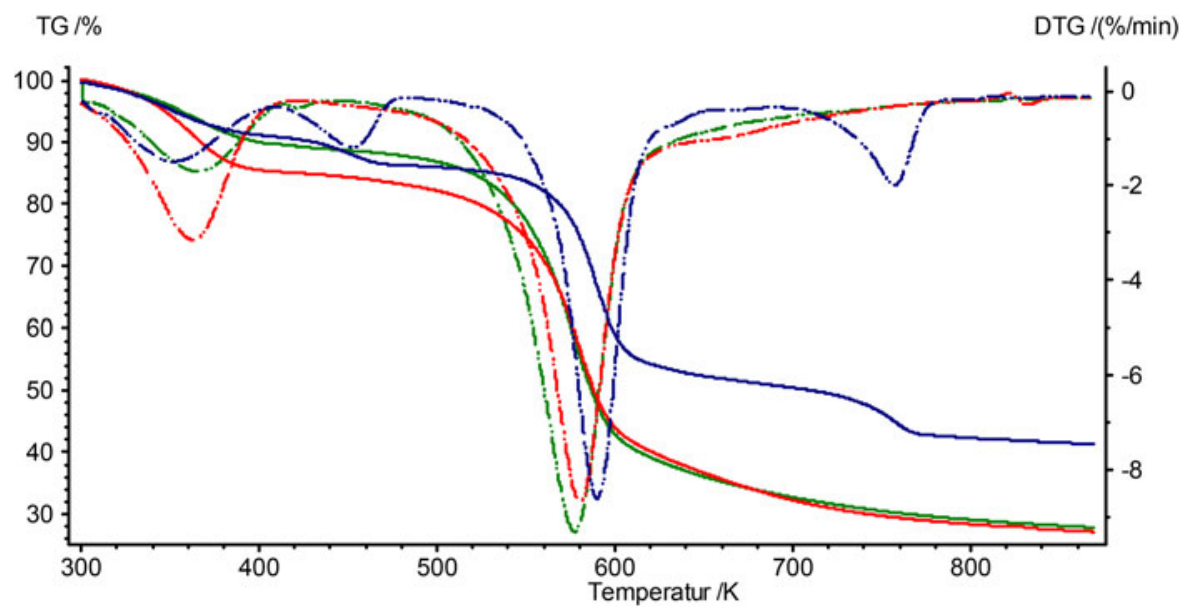

Fig. 1. TG and DTG profiles after hydration at RH =79\% in a desiccator: Circinaria gyrosa thalli (dark blue); Xanthoria elegans thalli (green) and Buellia frigida thalli (red); TG in solid lines, DTG in dashed/dotted lines.

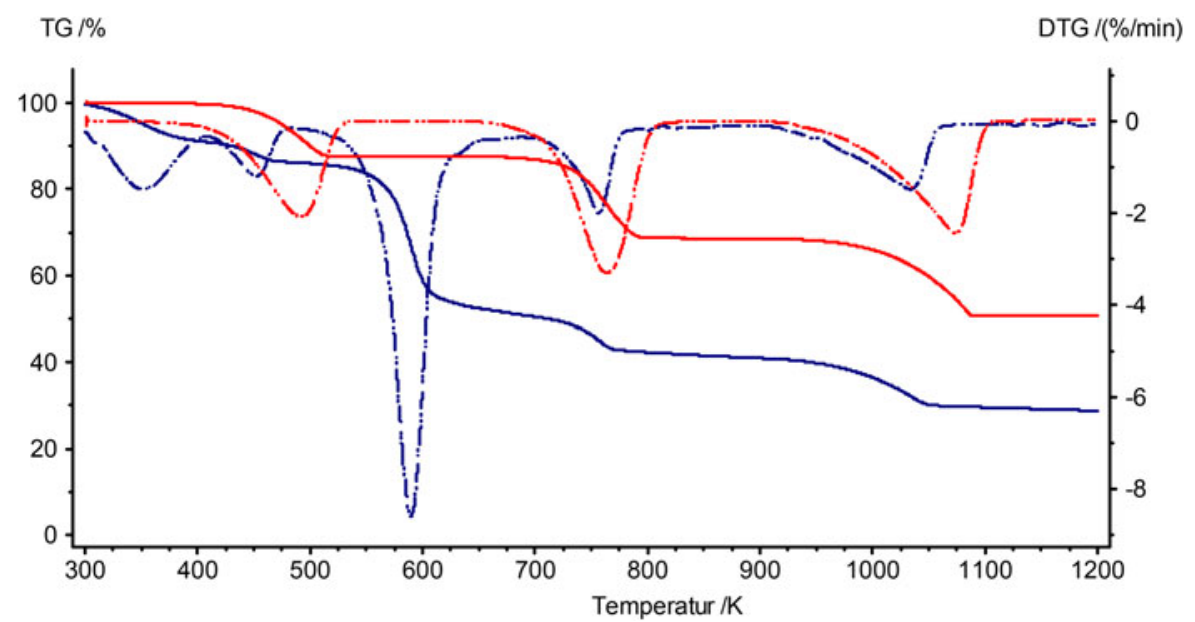

Fig. 2. TG and DTG profiles upon hydration at $\mathrm{RH}=79 \%$ in a desiccator: pure calciumoxalate monohydrate (red) and Circinaria gyrosa thalli (dark blue); TG in solid lines, DTG in dashed/dotted lines. All DTG-minima of calciumoxalate monohydrate and the lichen correspond with endothermic peaks in the DTA (not shown).

decomposition and carbonization process upon further heating exhibits two steps more in the TG of $C$. gyrosa when compared to $X$. elegans and $B$. frigida. The reason for that fact seems to be the extra component calciumoxalate monohydrate (whewellite) of C. gyrosa (Böttger et al. 2013). Whewellite is a monohydrate and decomposes in three steps according to Schultze (1971). Figure 2 depicts the three phases beginning with the release of the crystal water from $\mathrm{CaC}_{2} \mathrm{O}_{4} \cdot \mathrm{H}_{2} \mathrm{O}$ at $\sim 490 \mathrm{~K}$, the formation of $\mathrm{CaCO}_{3}$ with $\mathrm{CO}$ release at $\sim 760 \mathrm{~K}$, and the formation of $\mathrm{CaO}$ under release of $\mathrm{CO}_{2}$ at $\sim 1050 \mathrm{~K}$. According to the DTA results (not shown) these three steps are endothermal. Principally, these three phases were identified in the TG/DTG profiles of $C$. gyrosa as well (dark blue curve in Fig. 2). The temperatures of these steps differed slightly which is probably due to morphological differences between the synthetic and natural whewellite crystals in the lichen, e g. its size and distribution. Calciumoxalate monohydrate did not sorb any humidity at ambient temperature. So it showed no TG step below $450 \mathrm{~K}$ for the release of physisorbed water as did the lichen (Fig. 2). Equivalent to the DTG curve of B. frigida, the DTA profile (not shown) exhibits endothermic peaks except for the huge TG/DTG signal at about $600 \mathrm{~K}$. This considerable mass loss is not expressed in the DTA trace.

Figure 3 shows the TG and DTG curves of $B$. frigida, the mycobiont of $B$. frigida and pure synthetic chitin, one of the main dry weight components of mycobionts. The pure chitin showed a pattern in between the lichen and the two-step-curve of the mycobiont. Despite these differences, the main components of the released volatiles of all three samples were undoubtedly $\mathrm{H}_{2} \mathrm{O}$ and $\mathrm{CO}_{2}$. The second step of the mycobiont, however, includes some hydrocarbons as seen below.

After demonstrating the hydration and dehydration behaviour of lichens as an entire organism and of its isolated mycobiont, Figs 4 and 5 show the comparison of the TG/DTG profiles of B. frigida's mycobiont irradiated with different doses of UVC under dry and wet conditions. The curves of D0, D10 and D50 (Fig. 4) were characterized by three TG steps or DTG minima, respectively. The first minimum at 


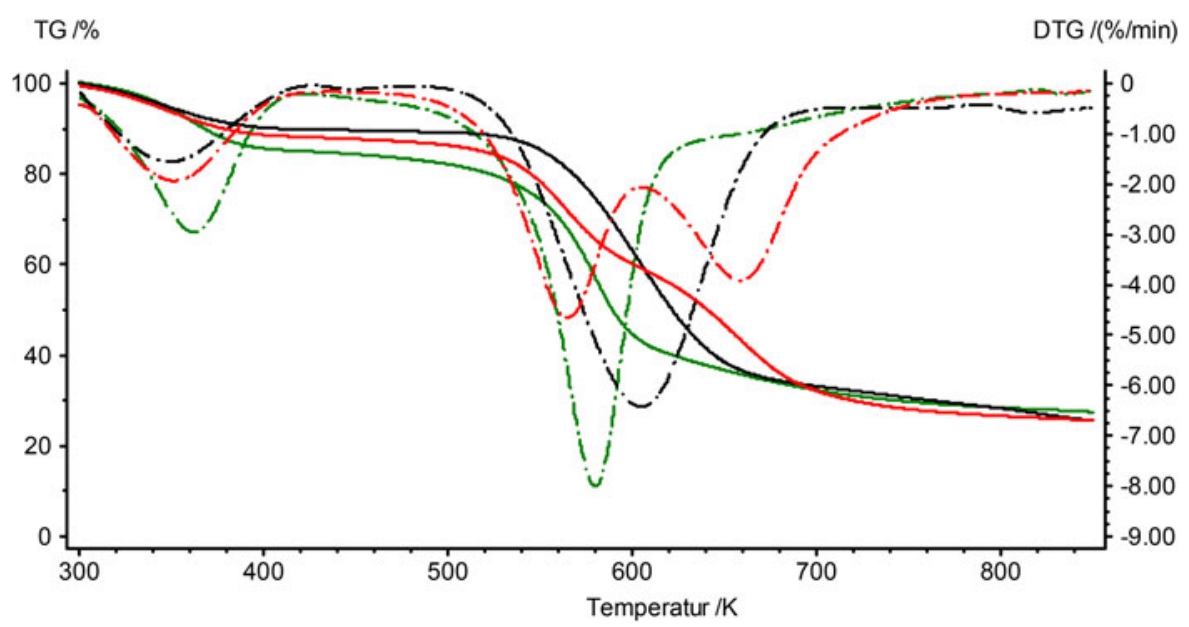

Fig. 3. TG and DTG profiles after hydration at $\mathrm{RH}=79 \%$ in a desiccator: comparison of Buellia frigida thalli (green), B. frigida mycobiont (red) and pure chitin (black); TG in solid lines, DTG in dashed/dotted lines.

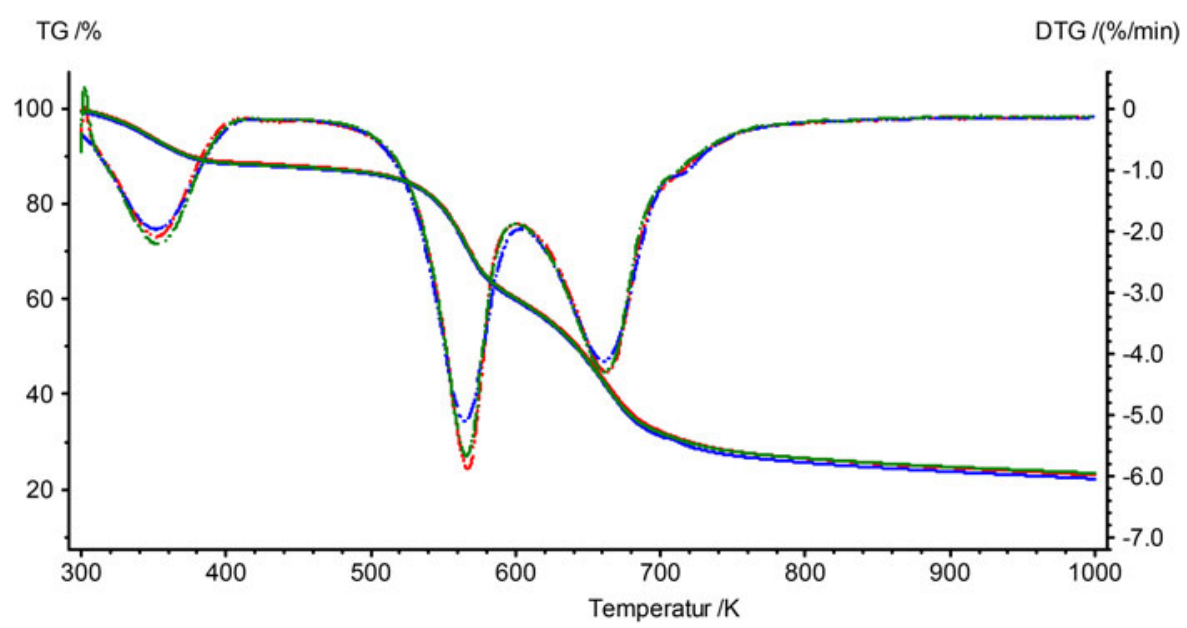

Fig. 4. TG and DTG profiles of the mycobiont of Buellia frigida after irradiation with UVC over 0,10 and $50 \mathrm{~h}$ under dry conditions: D0 (green), D10 (red) and D50 (blue). TG after hydration at RH $=79 \%$ in a desiccator. TG in solid lines, DTG in dashed/dotted lines.

$360 \mathrm{~K}$ indicated the release of physisorbed water. The second stage around $560 \mathrm{~K}$ was due to stronger bonded water or hydroxyls and the beginning decay. The last step at $660 \mathrm{~K}$ was dominated by the thermal decomposition of the mycobiont, in particular of its main component, i.e. chitin (sum formula of $\left.\left(\mathrm{C}_{8} \mathrm{H}_{12} \mathrm{NO}_{5}\right)_{n}\right)$.

The wet-irradiated samples (Fig. 5) show a very similar behaviour except a new step/minimum at $420 \mathrm{~K}$. This step increases with the doses of UVC indicating an impact of the UVC treatment on the release of stronger physisorbed water. To test this behaviour we repeated the irradiation experiments with the mycobiont of $X$. elegans but found no comparable effect (Fig. 6). Therefore we hypothesize that this effect is due to melanin, which is formed in large amounts and deposited in/on its cell wall by the mycobiont of $B$. frigida but not by the one of $X$. elegans. Melanin pigments are found to dissipate over $99.9 \%$ of absorbed UV radiation into heat (Meredith \& Riesz 2004), representing a potent PAR- and UVR-protective compounds. Strongly interacting with UVR, it might also be involved in the activation of additional UVC-induced sorption site for water such as the $-\mathrm{NH},-\mathrm{COOH}$ or $-\mathrm{OH}$ substituents. In support, it was already demonstrated that UVC $(254 \mathrm{~nm})$ changes the electronic structure of fungal melanin and enhances its electron transfer properties in the NADH redox reaction by a factor of 3.9 (Dadachova et al. 2007). Such interactions may also affect the water sorption properties of melanin as shown by the present study. Nonetheless, the mycobiont of $X$. elegans tended to sorb some more weakly-physisorbed water upon irradiation of the wet sample. This causes higher mass losses at $T<450 \mathrm{~K}$ and, may explain the higher total mass loss up to $900 \mathrm{~K}$. According to the results shown in Figs 4 and 5, this is not observed for B. frigida. As expected, the DTA exhibits an endothermal peak at $T=370 \mathrm{~K}$ and an exothermal one at $T=590 \mathrm{~K}$.

\section{TA-MS investigations}

The thermal behaviour of the mycobiont of $B$. frigida under $\mathrm{Ar}=$ argon is represented by the data in Figs 7 and 8 as obtained by online-coupled TA-MS measurements. Two main 


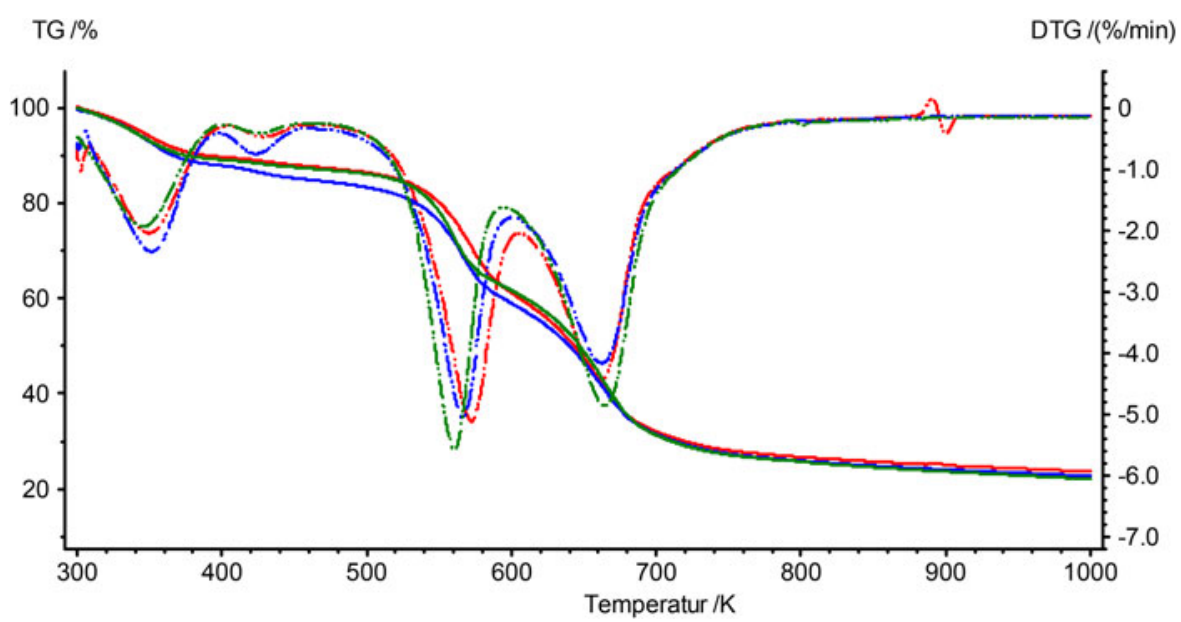

Fig. 5. TG and DTG profiles of the mycobiont of Buellia frigida after irradiation with UVC over 0,10 and $50 \mathrm{~h}$ under wet conditions: W0 (green), W10 (red) and W50 (blue). TG after hydration at RH $=79 \%$ in a desiccator. TG in solid lines, DTG in dashed/dotted lines.

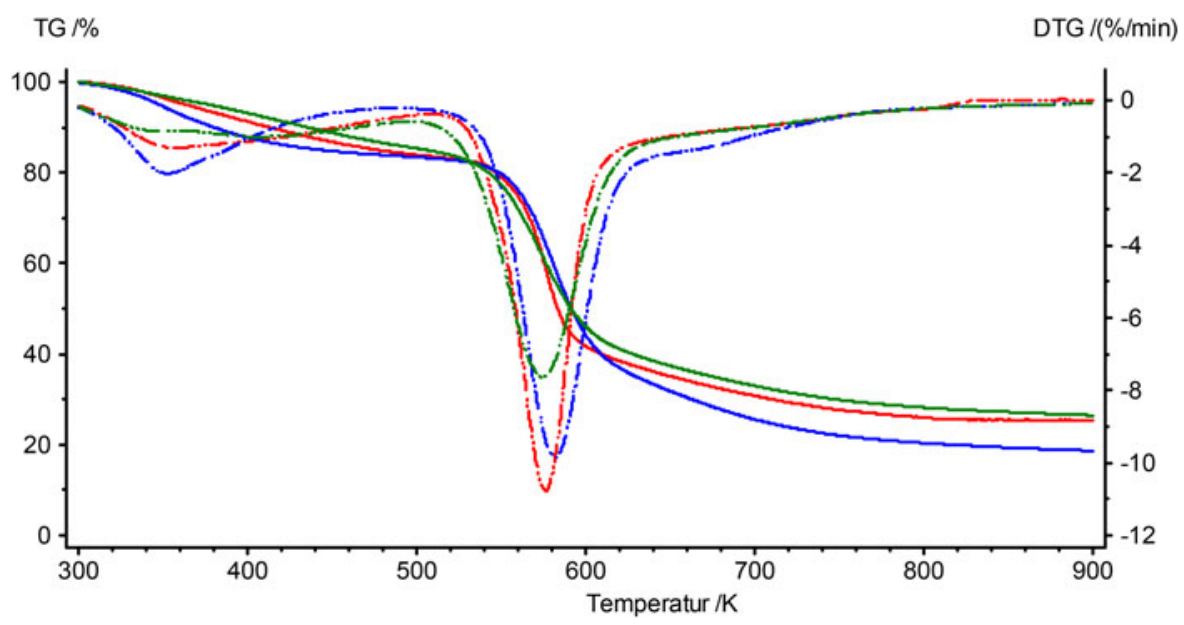

Fig. 6. TG and DTG profiles of the mycobiont of $X$. elegans after irradiation under dry and wet conditions for 50 h: non-irradiated control (green), D50 (red), W50 (blue). The DTA exhibited an endothermic peak at $T=370 \mathrm{~K}$ and an exothermic one at $T=590 \mathrm{~K}$. TG after hydration at $\mathrm{RH}=79 \%$ in a desiccator. $\mathrm{TG}$ in solid lines, DTG in dashed/dotted lines.

findings should be emphasized: first, the structured water release at ca. $415 \mathrm{~K}$ preceded by an additional shoulder at ca. $360 \mathrm{~K}$, and, second, the chemical information deduced from the fragments occurring during (and around!) the two main steps of the mycobiont decomposition (DTG maxima at 565 and $662 \mathrm{~K}$ ). The DTA traces are not shown in the plots as the weak exothermicity (under $\mathrm{N}_{2}$ ) of the two steps is still less pronounced under Ar. On the other hand, several details of the chemical processes during the thermal decomposition can be clearly deduced from an inspection of the ion current (IC) curves under Ar.

The TA data in Fig. 7 support our assumption that the wet irradiation causes the formation of additional adsorption sites for water and, furthermore, creates a greater mobility in the system, thus explaining the simultaneous release of water and $\mathrm{C}$-containing species already in the low-temperature range at ca. $415 \mathrm{~K}$. This is clearly evidenced by the IC intensities for $\mathrm{m} / \mathrm{z} 12$ and 44 appearing in parallel to the $\mathrm{m} / \mathrm{z} 18$.
The most important feature for a correct attribution of fragments to the same (or to another) molecule formed during a multi-step process is the identical (or non-identical) curve shape of different mass numbers to be assigned. So the mentioned parallel curvature of $\mathrm{m} / \mathrm{z} 12$ and 44 proves that they originate from the same molecule (most probably $\mathrm{CO}_{2}$ ), whereas $m / z 27$ only partly follows the qualitative shape of $m / z 12$. This means that the mass number $m / z 27$ does not represent the same molecule during the integral intensity evolution. It most probably indicates $\mathrm{C}_{2} \mathrm{H}_{3}^{+}$(unspecific for hydrocarbons) when compared with the $\mathrm{m} / \mathrm{z} 12$ curve, whereas about $660-700 \mathrm{~K}$ it indicates $\mathrm{HCN}$ (formed from chitin, see below).

If $\mathrm{m} / \mathrm{z} 12$ and 44 exhibit the same curvature, the most probable explanation is the attribution to $\mathrm{CO}_{2}$, but other molecules can contribute to the $\mathrm{m} / \mathrm{z} 44$ intensity as well. A considerable part of the organic matter indicated by the $\mathrm{CO}_{2}$ release can be chitin which is known to be an essential part of the cell walls of many fungi (Daum 2005). Chitin, containing the 


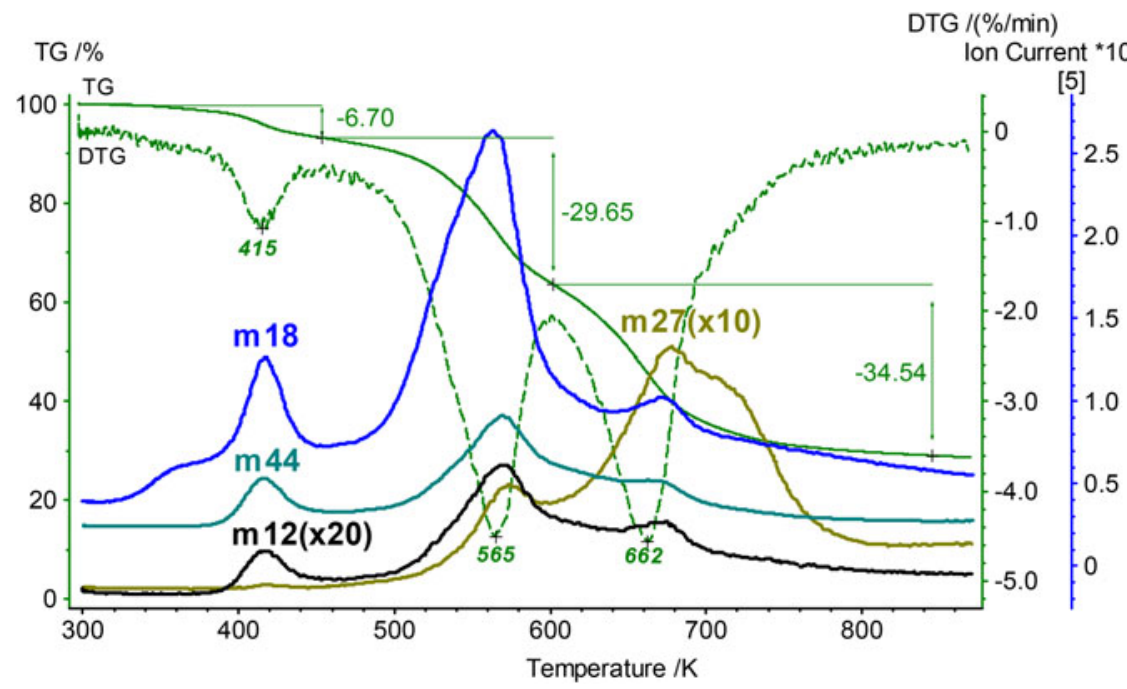

Fig. 7. TG-MS curves for the mycobiont of Buellia frigida, W50 (lab-dry) in Ar (Pt beakers) with the IC curves for the mass numbers $m / z$ 12( $\mathrm{C}^{+}$), $18\left(\mathrm{H}_{2} \mathrm{O}^{+}\right), 27\left(\mathrm{HCN}, \mathrm{C}_{2} \mathrm{H}_{3}^{+}\right)$and $44\left(\mathrm{CO}_{2}^{+}, \mathrm{CH}_{3} \mathrm{CHO}^{+}\right)$. The amplifications refer to the most intense IC signal $(\mathrm{m} / z$ 18), the intensity of which is given on the scale on the right hand. The IC curves are shifted for a better legibility. Note the qualitatively identical curve shape for 12 and 44 , but not for 18 (shoulder at $360 \mathrm{~K}$ ) and 27.

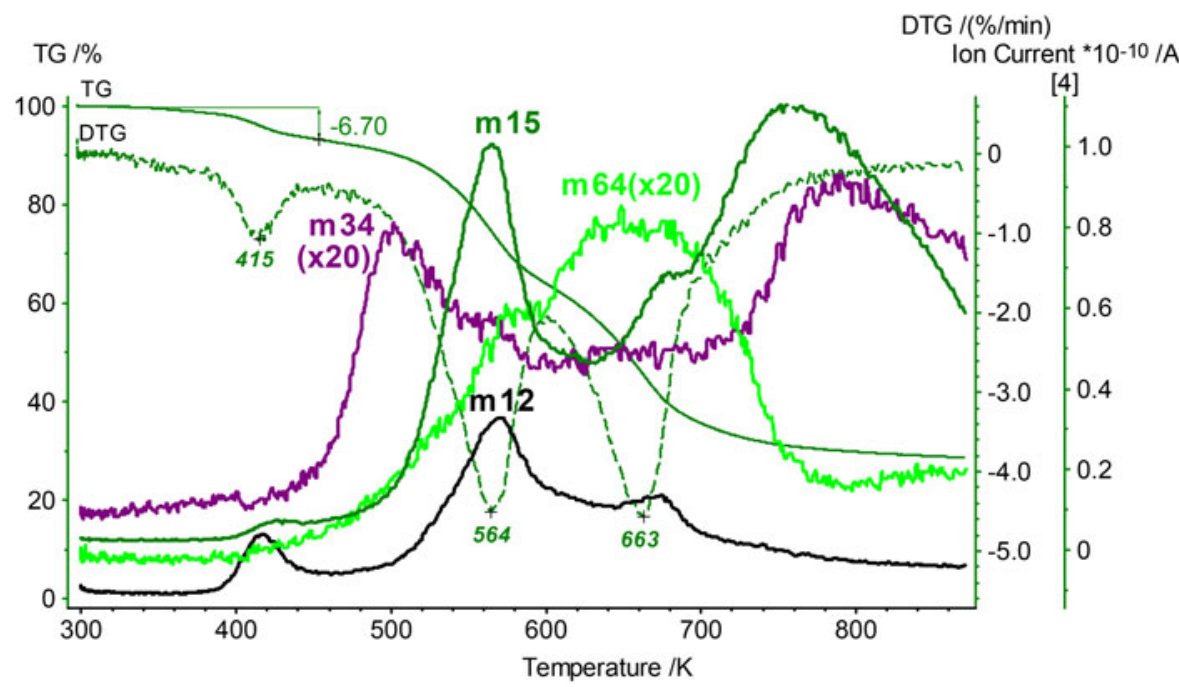

Fig. 8. As shown before in Fig. 7, here with the further mass numbers $15\left(\mathrm{CH}_{3}^{+},{ }^{15} \mathrm{~N}^{+}\right), 34\left(\mathrm{H}_{2} \mathrm{~S}^{+}\right)$and $64\left(\mathrm{SO}_{2}^{+}\right)$to be compared with $\mathrm{m} / \mathrm{z} 12\left(\mathrm{C}^{+}\right)$. In contrast to Fig. 7, $\mathrm{m} / \mathrm{z} 12$ is not amplified as all other fragments appear with a lower intensity than $\mathrm{H}_{2} \mathrm{O}$ or $\mathrm{CO}_{2}$. Again the IC curves are shifted.

acetamido group bound to a polysaccharide matrix, can explain not only the formation of $\mathrm{CO}_{2}$ via deacetylation (the wellknown chitosan process, Daum 2005), but also of HCN and of less-specific fragments such as $\mathrm{C}_{2} \mathrm{H}_{3}^{+}$. Furthermore, the $\mathrm{CH}_{3} \mathrm{CO}$ part of the acetamido group $(\mathrm{m} / \mathrm{z} 43)$ can contribute to $m / z 44$ after hydrogen attraction which is known not only for chemical reactions, but for reorganizations in the MS ionization chamber as well.

The 'early' organic matter together with the additional water release yields a mass loss of $6.7 \%$; it can be assumed, however, that the major part is due to water. Both the IC signal for $\mathrm{m} / \mathrm{z} 18$ and the DTG curve exhibit an additional shoulder at ca. $360 \mathrm{~K}$, thus indicating two different bonding situations of water: the shoulder, obviously, represents weaker bound water, i.e. the physisorbed one, whereas the main peak has to be attributed to water which was fixed as a consequence of the irradiation. Both water release steps can be detected in the data presented in Fig. 5 as well, but their intensity ratio differs. This is due to the humidity state of the sample measured with TA-MS: the sample was 'lab-dry' (no hydration at $\mathrm{RH}=79 \%$ ), therefore the first step/minimum of the physisorbed water at $360 \mathrm{~K}$ is lacking in Fig. 7. The two following water release steps with IC maxima at 560 and $670 \mathrm{~K}$ have to be explained by another chemical process: this is so-called reaction water which is, together with $\mathrm{CO}_{2}$, the product of multiple decomposition and innermolecular redox reactions upon decomposition. 


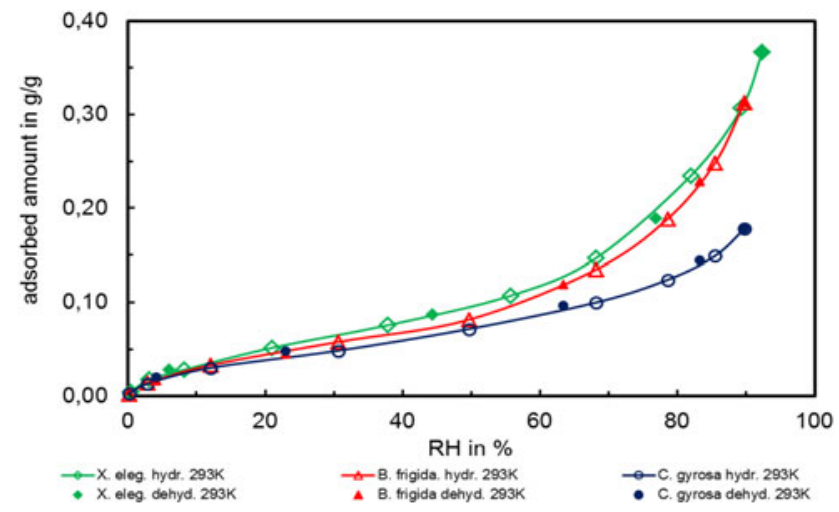

Fig. 9. Comparison of the water sorption isotherms at $293 \mathrm{~K}\left(+20^{\circ} \mathrm{C}\right)$ of the lichens Xanthoria elegans (green), Buellia frigida (red) and Circinaria gyrosa (blue, from top to bottom) as a function of RH.

In Fig. 8 further fragment intensities are shown. Especially $m / z 34\left(\mathrm{H}_{2} \mathrm{~S}^{+}\right)$and $64\left(\mathrm{SO}_{2}^{+}\right)$clearly prove the presence of sulphurcontaining substances. Please note that the intensity evolution of $m / z 34$ and 64 is quite different from those for $m / z 12,15$, 18 and, obviously, represent independent decomposition steps.

\section{Isotherm measurements}

The reversibly physisorbed water, sorbed at $\mathrm{RH}=79 \%$ and released in the TG at $T<450 \mathrm{~K}$, was investigated in more detail by hydration/dehydration isotherm measurements. Figure 9 gives an overview for all three lichens at $T=293 \mathrm{~K}$. As expected by the TG results documented in Fig. 1, the water uptake of $C$. gyrosa was retarded compared to the other two lichens starting at around $\mathrm{RH}=50 \%$. The samples for the TG experiment were saturated at $\mathrm{RH}=79 \%$ so that the comparison has to refer to the respective value in Fig. 9. The isotherm measurements confirm the $\mathrm{TG}$ results in respect to changes in the water retention ability of lichens adapted to different environmental conditions. Interestingly, the isotherms become steeper at $\mathrm{RH}>80 \%$ where the thallus water content was found to be sufficient to start photosynthesis in various lichen species (Lange 1969; Sigfridsson \& Oquist 1980; Lange et al. 1986). With rising $\mathrm{RH}$ the lichens sorb more and more water at polar groups and other sites of their polymeric materials culminating in pure condensation at surfaces when approaching $\mathrm{RH}=100 \%$. The latter may also happen in mesopores or small $\mu \mathrm{m}$-pores of the thallus as reported by Valladares et al. (1993) for another family of lichens.

Regardless of the hydration mechanism, the isotherms provided a quantitative information about the amount of physisorbed water if the RH (or $a_{\mathrm{w}}$ ) of the lichens environment is known. Measurements at various temperatures gave detailed thermodynamic information of the sorption system. The Figs 10-12 summarize the results of the water physisorption behaviour at different temperatures found for C. gyrosa (Fig. 10) and B. frigida. (Figs 11 and 12). The measurements were performed close to Martian environmental conditions in terms of temperature and pressure. The tested temperatures of 293, 273 and $255 \mathrm{~K}$ meet those frequently found during the Martian

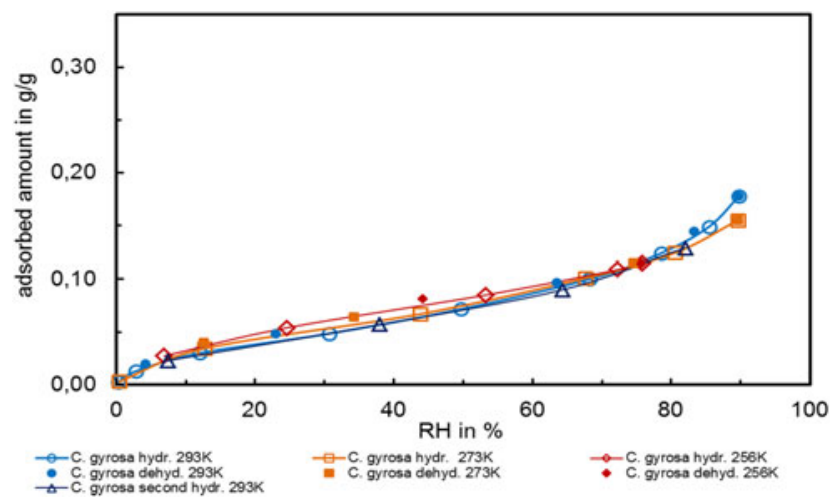

Fig. 10. Identical hydration/dehydration isotherms of the lichen Circinaria gyrosa at $256 \mathrm{~K}\left(-17^{\circ} \mathrm{C}\right.$, red $), 273 \mathrm{~K}\left(0^{\circ} \mathrm{C}\right.$, orange $)$ and 293 $\mathrm{K}\left(+20^{\circ} \mathrm{C}\right.$, blue $)$ as a function of $\mathrm{RH}$.

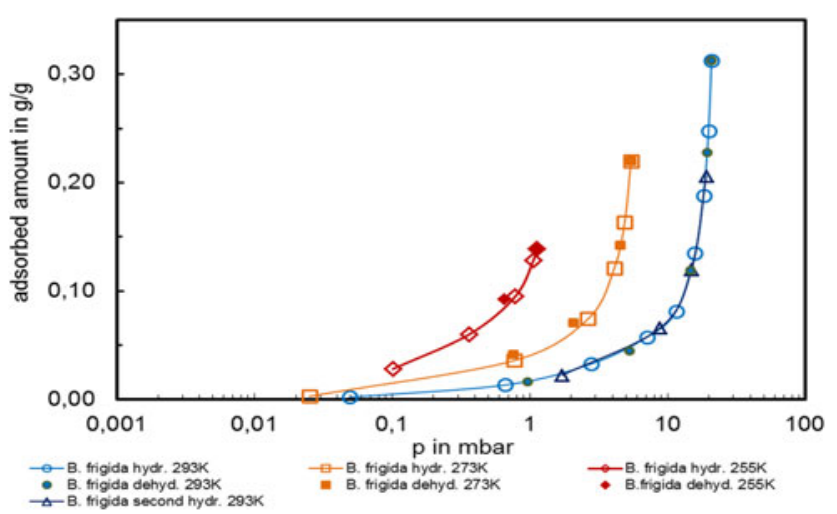

Fig. 11. Hydration/dehydration isotherms of the lichen Buellia frigida at $255 \mathrm{~K}\left(-18^{\circ} \mathrm{C}\right.$, red $), 273 \mathrm{~K}\left(0^{\circ} \mathrm{C}\right.$, orange $)$ and $293 \mathrm{~K}\left(+20^{\circ} \mathrm{C}\right.$, blue $)$ as a function of vapour pressure. Note the logarithmic $x$-axis.

day in equatorial and subtropical regions while the applied atmospheric pressure range ( $<20$ mbar, but comprised of water vapour only) is equivalent to that of the Martian atmosphere, which is ranging from 6 mbar at zero elevation level to ca. 11.6 mbar at the bottom of Hellas Planitia. To exemplify the vapour pressure values, the isotherms of $B$. frigida are plotted in Fig. 11 as a function of the absolute pressure as they were experimentally determined. If the isotherms are recalculated and plotted as a function of the RH, all isotherms for different temperatures of one organism should be found in one bundle of curves. The value of RH is the relative pressure (or $a_{\mathrm{w}}$ ) multiplied by 100. C. gyrosa in Fig. 10 perfectly fulfilled this condition following the thermodynamic rules.

Interestingly, B. frigida (Fig. 12) deviates from this rule and showed clear temperature-dependence between $298 \mathrm{~K}\left(+20^{\circ} \mathrm{C}\right)$ and the lower temperatures of $273 \mathrm{~K}\left(0^{\circ} \mathrm{C}\right)$ and $256 \mathrm{~K}\left(-17^{\circ} \mathrm{C}\right)$. A repeated determination of the isotherm at $298 \mathrm{~K}$ (indicated as second hydration in Figs 11 and 12) gives an identical curvature. It is important to note that these measurements were performed after the determination of the isotherms at the lower temperatures and at the same sample. A comparison of the two single symbionts of $B$. frigida in Fig. 13 with the entire 


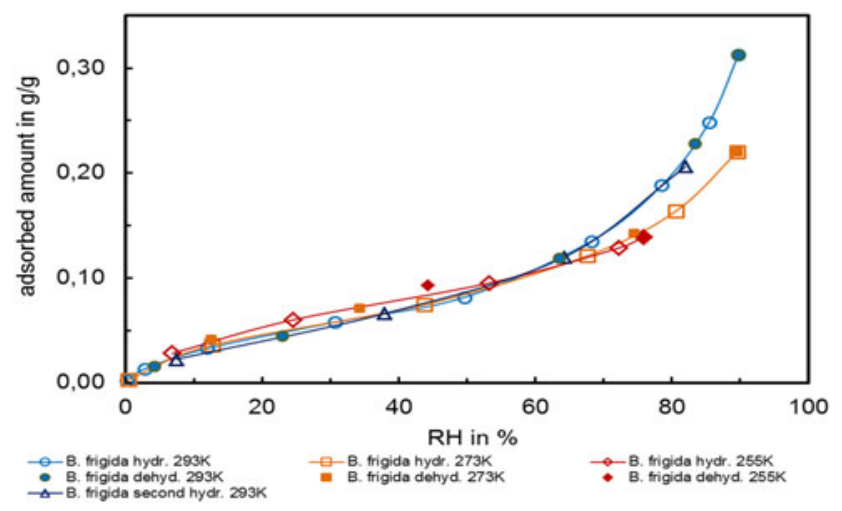

Fig. 12. Hydration/dehydration isotherms of the lichen Buellia frigida at $255 \mathrm{~K}\left(-18^{\circ} \mathrm{C}\right.$, red $), 273 \mathrm{~K}\left(0^{\circ} \mathrm{C}\right.$, orange $)$ and $293 \mathrm{~K}\left(+20^{\circ} \mathrm{C}\right.$, blue $)$ as a function of RH.

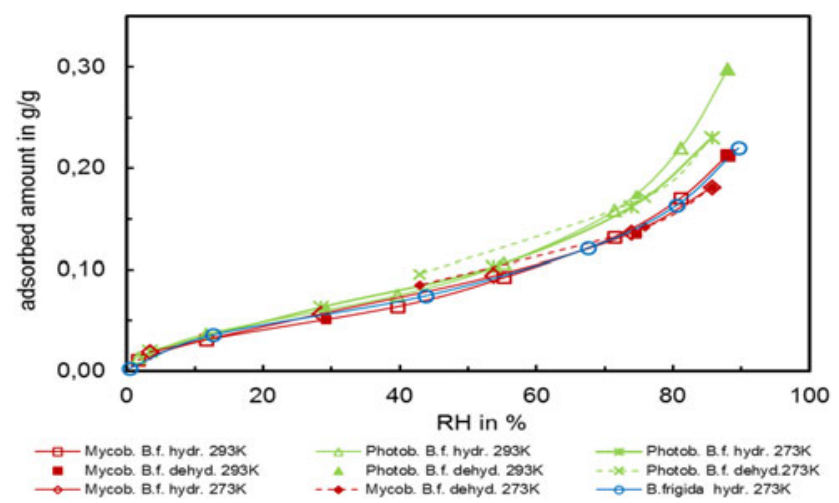

Fig. 13. Hydration/dehydration isotherms of the lichen Buellia frigida at $273 \mathrm{~K}\left(0^{\circ} \mathrm{C}\right.$, blue); its isolated photobiont (green) and its isolated mycobiont (red) at $273 \mathrm{~K}\left(0^{\circ} \mathrm{C}\right)$ and $293 \mathrm{~K}\left(+20^{\circ} \mathrm{C}\right)$, respectively, as a function of $\mathrm{RH}$.

lichen thallus does not give an obvious explanation of this 'non-conformist' behaviour; it could not be consistently attributed to one of the two symbionts. At $T=273 \mathrm{~K}$ or lower the isotherm of the entire lichen is very close to that of the mycobiont and at $T=298 \mathrm{~K}$ the isotherm of the photobiont is close to the symbiotic lichen organism.

The results consistently stressed the full reversibility of the isothermes (water uptake and release exhibit the same curvature) and revealed relatively fast kinetics of the hydration/dehydration process. In all investigated lichens the time required for equilibration ranged between minutes and ca. $1 \mathrm{~h}$, whereas, as an example from own non-published work, Nostoc commune or an unspecified moss species required more than a day. These observations are in line with the poikilohydric nature of lichens. On the one hand, lichens are able to take up water quickly and thus enhance the utilization of limited water supply. On the other hand, many lichen species do not retain water but also desiccate as rapidly. Lichens are more susceptible to damaging effects of high levels of UVR and heat when wet (Kappen \& Valladares 1999). Therefore, rapid desiccation in case of unfavourable environmental conditions resembles a protective adaptation and fast shifts in the hydration status allow poikilohydric organisms to profit by favourable conditions but to omit unfavourable ones.

Besides liquid water, high air humidity ( $\geq 80$ to $97 \%$, Sigfridsson \& Oquist 1980; Lange et al. 1986) result in rehydration and activation of the lichen metabolism and the optima for photosynthesis were found to be rather low in drought-adapted lichens (as 65\% in Umbilicaria pustulata90\% in Peltigera canina, Ried 1960; Smith 1962). Lichen photosynthesis can reach its maximum at relatively low water content and depends on habitat-specific adaptations (Henssen \& Jahns 1974). For example, the lichen Ramalina maciformis reaches its $\mathrm{CO}_{2}$-compensation point $\left(\mathrm{CO}_{2}\right.$-uptake by photosynthesis compensates $\mathrm{CO}_{2}$-evolution by respiration) at ca. $80 \% \mathrm{RH}$ which resembles ca. $20 \%$ of thallus water content (TWC, Lange 1969). At 30\% TWC the lichen obtains 50\% of its maximum photosynthetic rate which is reached at $60 \%$ TWC. At the natural habitat, such metabolic re-activation is possible by rising air humidity and dewfall during night, leading to positive net photosynthesis and up to $90 \%$ of maximum photosynthesis rate after 6-8 h of exposure in saturated air (Lange 1969). The present results (Fig. 9) show that such physiologically relevant TWC for dry-adapted lichens of $\geq 20 \%$ is achieved during the course of the experiments by the lichens $X$. elegans and B. frigida, but not by C. gyrosa at $293 \mathrm{~K}\left(+20^{\circ} \mathrm{C}\right)$. B. frigida showed a maximum TWC of $30 \%$ and $X$. elegans of $35 \%$ while $C$. gyrosa did not surpass $18 \%$ TWC. Moreover, temperature-dependent measurements of hydration/dehydration isotherms show that $B$. frigida achieves $>20 \%$ TWC at $273 \mathrm{~K}\left(0^{\circ} \mathrm{C}\right)$ but not at $255 \mathrm{~K}\left(-18^{\circ} \mathrm{C}\right) ; C$. gyrosa did not reach a TWC $>18 \%$ at any of the measured temperatures (Figs 10-12). The results of the isolated symbionts of $B$. frigida demonstrate slightly higher hydration rates for the photobiont than the mycobiont at $>50 \%$ RH (Fig. 13). Hale (1976) reported that the respiration of a lichen (to which the mycobiont is the main contributor) decreases faster with desiccation than the photosynthesis (performed only by the photobiont). The present results suggest that the hydration state of the photobiont is higher than that of the mycobiont, reaching the crucial hydration level of ca. 20\% TWC at lower air humidity (Fig. 13).

Finally, the impact of UVC irradiation on the hydration/dehydration isotherms of a symbiont, as a first step, will be discussed. Figure 14 shows the sorption isotherms of water on the untreated mycobiont of B. frigida and the irradiated W50 sample, respectively. The isotherms are plotted again as a function of the RH. There is an obvious difference between both samples at $\mathrm{RH}>70 \%$. The wet irradiated sample sorbs more water compared with the untreated mycobiont which is in line with the TG results showing some extra physisorbed water (step at $420 \mathrm{~K}$ ).

As already discussed for the TG/DTG analysis, the UVC-treatment apparently improved the ability of physisorption of water by creating extra sorption sites in the mycobiont. This may be due to the presence of melanin in the mycobiont of $B$. frigida. Melanin is an aromatic polymer with polar ligands such as $\mathrm{OH}$, aldehyde and carboxyl groups being well-known as specific sorption sites for water. Another explanation may 


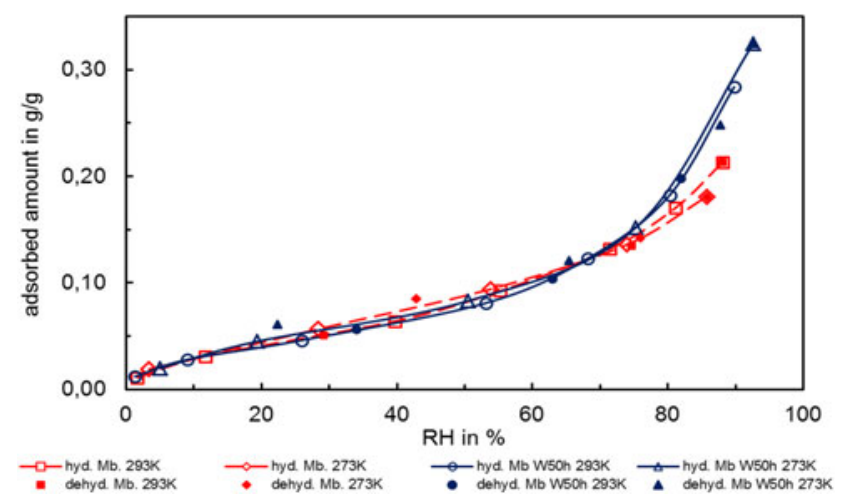

Fig. 14. Hydration/dehydration isotherms of the mycobiont of Buellia frigida at $273 \mathrm{~K}\left(0^{\circ} \mathrm{C}\right)$ and $293 \mathrm{~K}\left(+20^{\circ} \mathrm{C}\right)$ without UVC irradiation (red) and after $50 \mathrm{~h}$ of irradiation in the wet state (blue) as a function of RH.

be the 'damage' of parts of the acetamido groups of the chitin in B. frigida upon UVC exposure. Thus, irradiation of these components of the wet mycobiont change the polarity of their specific groups and stronger sorption sites for the water molecule could be formed.

\section{Conclusion}

Besides general information on the complete decomposition at elevated temperatures, the thermoanalytic investigations, including mass spectroscopy, of the lichens $X$. elegans, $B$. frigida and $C$. gyrosa, yielded valuable information about their water physisorption, dehydroxylation and decarboxylation behaviour. Calciumoxalate monohydrate significantly influenced the decomposition pattern of $C$. gyrosa and was recently reported as a particular intermedullary component (Böttger et al. 2013).

In regard to water retention properties, the gravimetric hydration/dehydration studies close to Martian environmental conditions revealed differences between C. gyrosa (adapted to dry warm conditions) on the one hand, and $X$. elegans and $B$. frigida (adapted to cold arctic or alpine conditions) on the other hand. C. gyrosa is less hydrophilic than the other two lichens, leading to a maximum TWC $<20 \%$, while $B$. frigida, $X$. elegans as well as the isolated symbionts of $B$. frigida were found to achieve TWC values of 30-35\% when the air humidity exceeds $80 \%$ RH. A TWC of $>20 \%$ was found to be crucial to re-activate photosynthesis in drought-adapted lichens (Lange 1969). Thus, it might be hypothesized that - at least to some extent $-B$. frigida and $C$. gyrosa could accumulate enough water to become metabolically active during the hydration and dehydration experiments under the conditions described above. Furthermore, the present results indicate that exposure to UVC - a stressor not found on Earth but on Mars or in space - may influence the water retention ability of organisms. Under wet exposure conditions, the mycobiont of $B$. frigida formed additional water sorption sites. Since a similar reaction is not found in the mycobiont of $X$. elegans, that effect might be attributed to melanin which is only produced by the mycobiont of $B$. frigida. Another effect might be the increasing 'damage' of the acetamido groups of the chitin upon UVC exposure. Nonetheless, chitin is the dominant cell wall component in both mycobionts while the peculiar effect is only found in the mycobiont of $B$. frigida. However, these two options might be interpreted as first indicators of UVC-induced damage.

In general, the examination of the water sorption properties of organisms may contribute to an improved understanding of important astrobiological topics, as the resistance of extremotolerants and extremophiles towards harsh and/or extraterrestrial environmental factors, their capacity to thrive under conditions of limited water availability, and the damages induced by exposure to such conditions. These experiments may support a deeper evaluation of in-situ climatic measurements from Mars in the context of astrobiology. With respect to the occasionally high water vapour content in the Martian atmosphere (Kieffer et al. 1977), the water uptake of lichens from air humidity alone and above the level of physiological activity might be of further interest. Because B. frigida and C. gyrosa are astrobiological model lichens and part of the current BIOMEX space exposure mission, the present results obtained from both of these currently investigated organisms will also enlarge our knowledge about possible effects on the physical and physiological properties of lichens caused by the conditions of space and Mars-like exposure on the International Space Station.

\section{Acknowledgements}

This research was supported by the Helmholtz Association through the research alliance 'Planetary Evolution and Life' and is part of the current BIOMEX mission (ESA call, 2009, Ref.-No. ILSRA-2009-0834).

\section{References}

Bibring, J-P. et al. (2005). Mars surface diversity as revealed by the OMEGA/ Mars Express observations. Science 307(5715), 1576-1581.

Böttger, U., Meeßen, J., de la Torre, R., Frias, J.M., Rull, F., Sánchez, F.J., Hüber, H.W. \& de Vera, J.-P. (2013). Raman spectroscopic analysis of Circinariagyrosa as a candidate for BIOMEX. Int. J. Astrobiol. 13(1), 19-27, doi: 10.17/S1473550413000293

Brandt, A., de Vera, J.-P., Onofri, S. \& Ott, S. (2014). Viability of the lichen Xanthoriaelegans and its symbionts after 18 months of space exposure and simulated Mars conditions on the ISS. Int. J. Astrobiol., publ. online 2014, doi: $10.1017 / \mathrm{s} 1473550414000214$

Briggs, G., Klaasen, K., Thorpe, T., Wellman, J. \& Baum, W. (1977). Martian dynamical phenomena during June-November 1976: viking Orbiter imaging results. J Geophys. Res. 82(A28), 4121-4149.

Christensen, P.R. (2006). Water at the poles and in permafrost regions of mars. Elements 2(3), 151-155.

Dadachova, E., Bryan, R.A., Huang, X., Moadel, T., Schweitzer, A.D., Aisen, P., Nosanchuk, J.D. \& Casdevall, A. (2007). Ionizing radiation changes the electronic properties of melanin and enhances the growth of melanized fungi. PloS one. 2(5), e457.

Daum, G. (2005). Aerobe Deprotonierung von Crustacean-Abfällen zur Gewinnung von Chitin mittels proteolytischer Mikroorganismen, Thesis, University of Hamburg, 2005.

Davies, D.W. (1979). The relative humidity of Mars' atmosphere. J. Geophys. Res. 84(B14), 8335-8340.

de la Torre, R., Sancho, L.G., Pintado, A., Rettberg, P., Rabbow, E., Panitz, C., Deutschmann, U., Reina, M. \& Horneck, G. (2007). BIOPAN experiment LICHENS on the Foton M2 mission: pre-flight verification 
tests of the Rhizocarpongeographicum-granite ecosystem. Adv. Space Res. 40(11), 1665-1671.

de la Torre, R. et al. (2010). Survival of lichens and bacteria exposed to outer space conditions - Results of the Lithopanspermia experiments. Icarus $\mathbf{2 0 8}$ (2), 735-748.

de Vera, J.P., Horneck, G., Rettberg, P. \& Ott, S. (2003). The potential of the lichen symbiosis to cope with the extreme conditions of outer space I. Influence of UV radiation and space vacuum on the vitality of lichen symbiosis and germination capacity. Int. J. Astrobiol. 1(1), 285-293.

de Vera, J.P., Horneck, G., Rettberg, P. \& Ott, S. (2004a). The potential of the lichen symbiosis to cope with the extreme conditions of outer space II: germination capacity of lichen ascospores in response to simulated space conditions. Adv. Space Res. 33, 1236-1243.

de Vera, J.P., Horneck, G., Rettberg, P. \& Ott, S. (2004b). In the context of panspermia: May lichens serve as shuttles for their bionts in space? In Proceedings of the third European Workshop on Astrobiology, pp. 197198. ESA SP-545, ESA Publications Division, ESTEC, Noordwijk.

de Vera, J.P., Rettberg, P. \& Ott, S. (2008). Life at the limits: capacities of isolated and cultured lichensymbionts to resist extreme environmental stresses. Orig. Life Evol. Biosph. 38, 457-468.

de Vera, J.P., Möhlmann, D., Butina, F., Lorek, A., Wernecke, R. \& Ott, S. (2010). Survival potential and photosynthetic activity of lichens under Mars-like conditions: a laboratory study. Astrobiology 10(2), 215-227.

de Vera, J.P., Schulze-Makuch, D., Khan, A., Lorek, A., Koncz, A., Möhlmann, D. \& Spohn, T. (2013). Adaptation of an Antarctic lichen to Martian niche conditions can occur within 34 days. Planet Space Sci. $\mathbf{9 8 ,}$ 182-190. doi: 10.1016/j.pss.2013.07.014

Emmerich, W.D. \& Post, E. (1997). Simultaneous thermal analysis - Mass spectrometer skimmer coupling system. J. Therm. Anal. 49, 1007-1012.

Farmer, C.B., Davies, D.W., Holland, A.L., LaPorte, D.D. \& Doms, P.E. (1977). Mars: water vapor observations from the Viking orbiters. $J$. Geophys. Res. 82(B28), 4225-4248.

Feldman, W.C., Prettyman, T.H., Maurice, S., Plaut, J.J., Bish, D.L., Vaniman, D.T. \& Tokar, R.L. (2004). Global distribution of near-surface hydrogen on Mars. J. Geophys. Res. 109(E9), 1-13, doi: 10.1029/2003JE002160

Grotzinger, J.P. et al. (2014). A habitable fluvio-lacustrineenvironment at yellowknife bay, gale crater, mars. Science 343(6169), 1242777. doi: $10.1126 /$ science. 1242777

Hale, M.E. (1976). The Biology of Lichens, pp. 37-39. Edward Arnold Publishers, London.

Hanss, J., Kalytta, A. \& Reller, A. (2003). Potentials and limitations of the skimmer MS system, hyphenated techniques in thermal analysis. In Proceedings of the 5th SelberKopplungstage, ed. Kapsch, E. \& Hollering, M., pp. 151-163. Bad Orb, Germany (May 25-28, 2003).

Harańczyk, H., Pytel, M., Pater, Ł. \& Olech, A. (2008). Deep dehydration resistance of antarctic lichens (genera Umbilicaria and Ramalina) by proton NMR and sorbtion isotherm. Antarctic Sci.. Cambridge University Press, 20(6), 527-535.

Hassler, D.M. et al. (2014). Mars' surface radiation environment measured with the Mars Science Laboratory's Curiosity Rover. Science 343(6169), 1244797. doi: 10.1126/science. 1244797

Hecht, M.H. et al. (2009). Detection of perchlorate and the soluble chemistry of Martian soil at the phoenix lander site. Science 325(5936), 64-67.

Henssen, A. \& Jahns, H.-M. (1974). Lichenes, pp. 138-149. Eine Einführung in die Flechtenkunde. Georg Thieme Verlag, Stuttgart.

Hess, S.L., Henry, R.M., Leovy, C.B., Ryan, J.A. \& Tillman, J.E. (1977). Meteorological results from the surface of Mars: viking 1 and 2. $J$. Geophys. Res. 82(A28), 4559-4574.

Hill, J.O. (1991). For Better Thermal Analysis III, Special Edition of the International Confederation for Thermal Analysis (ICTA), University of Rome.

Houtkooper, J.M. \& Schulze-Makuch, D. (2009). Possibilities for the detection of hydrogen peroxide-water-based life on Mars by the Phoenix Lander. Planet Space Sci. 57(4), 449-453.

Houtkooper, J.M. \& Schulze-Makuch, D. (2010). The possible role of perchlorates for Martian life. J Cosmol 5, 930-939.
Hubbard, G., Naderi, F. \& Garvin, J. (2002). Following the water, the new program for Mars exploration. Acta Astronaut 51, 337-350.

Jakosky, B.M., Nealson, K.H., Bakermans, C., Ley, R.E. \& Mellon, M.T. (2003). Subfreezing activity of microorganisms and the potential habitability of Mars' polar regions. Astrobiology 3(2), 343-350.

Jänchen, J., Meeßen, J., Ott, S., Sànches, F.J. \& de la Torre, R. (2013). Low temperature interaction of humidity with the lichens Buelliafrigida and Circinariagyrosa. Extended abstract No. 1504, In Proc. of the 44th LPSC 2013.

Jänchen, J., Bauermeister, A., Feyh, N., de Vera, J.-P., Rettberg, P., Flemming, H.-C. \& Szewzyk, U. (2014a). Water retention of selected microorganisms and Martian soil simulants under close to Martian environmental conditions. Planet Space Sci. 98, 163-168.

Jänchen, J., Herzog, T.H., Meeßen, J., Ott, S., Feist, M. \& de Vera, J.-P.P. (2014b). Impact of UVC exposure on the water retention of the lichen Buelliafrigida. Extended abstract No 1260, In Proc. of the 45th LPSC 2014

Kaisersberger, E. \& Post, E. (1997). Practical aspects for the coupling of gas analytical methods with thermal-analysis instruments. Thermochim. Acta 295, 73-93.

Kappen, L. (1973). Environmental response and effects. Response to extreme environments. In The Lichens, ed. Ahmadjian, V. \& Hale, M.E., pp. 346348. Academic Press, New York, London.

Kappen, L. (1988). Ecophysiological relationships in different climatic regions. In CRC Handbook of Lichenology, ed. Galun, M., vol. II, pp. 37-99. CRC Press, Boca Ranton.

Kappen, L. (1993). Plant activity under snow and ice, with particular reference to lichens. Arctic 46(4), 297-302.

Kappen, L. \& Valladares, F. (1999). Opportunistic growth and desiccation tolerance: the ecological success of poikilohydrous autotrophs. In Handbook of Functional Plant Ecology, ed. Pugnaire, F.I. \& Valladares, F., pp. 9-80. Marcel Dekker, Basel.

Kieffer, H.H., Martin, T.Z., Peterfreund, A.R., Jakosky, B.M., Miner, E.D. \& Palluconi, F.D. (1977). Thermal and albedo mapping of Mars during the Viking primary mission. J. Geophys. Res. 82(A28), pp. 4249-4291.

Kranner, I., Cram, W.J., Zorn, M., Wornik, S., Yoshimura, I., Stabentheiner, E. \& Pfeifhofer, H.W. (2005). Antioxidants and photoprotection in a lichen as compared with its isolated symbiotic partners. Proc. Natl Acad. Sci. USA 102(8), 3141-3146.

Lange, O.L. (1969). Experimentell-ökologische Untersuchungen an Flechten der Negev-Wüste. I. CO2-Gaswechsel von Ramalinamaciformis (Del.) Bory unter kontrollierten Bedingungen im Laboratorium. Flora 158, 324-333.

Lange, O.L. (1992). Pflanzenleben unter Stress, pp. 213-217. Echter Würzburg Fränkische Gesellschaftsdruckerei und Verlag, Würzburg.

Lange, O.L., Kilian, E. \& Ziegler, H. (1986). Water vapor uptake and photosynthesis of lichens: performance differences in species with green and blue-green algae as phycobionts. Oecologia 71, 104-110.

Lange, O.L., Green, T.G.A. \& Reichenberger, H. (1999). The response of lichen photosynthesis to external $\mathrm{CO}_{2}$ concentration and its interaction with thallus water-status. J Plant Physiol. 154, 157-166.

Lange, O.L., Green, T.G.A. \& Heber, U. (2001). Hydration-dependent photosynthetic production of lichens: what do laboratory studies tell us about field performance. J. Exp. Bot., Special Issue 52(363), 2033-2042.

Malin, M.C., Edgett, K.S., Posiolova, L.V., McColley, S.M., Dobrea, E.Z. \& Noe, E.A. (2006). Present-day impact cratering rate and contemporary gully activity on Mars. Science 314(5805), 1573-1577.

Marchant, D.R. \& Head, J.W. (2007). Antarctic dry valleys: microclimate zonation, variable geomorphic processes, and implications for assessing climate change on Mars. Icarus 192, 187-222.

McBain, J.W. \& Bakr, A.M. (1926). A new sorption balance. J. Am. Chem. Soc. 48, 690.

McEwen, A.S., Dundas, C.M., Mattson, S.S., Toigo, A.D., Ojha, L., Wray, J.J., Chojnacki, M., Byrne, S., Murchie, S.L. \& Thomas, N. (2012). Recurring slope lineae in equatorial regions of Mars. Nat. Geosci. 7, 53-58.

McKay, C.P., Friedmann, E.I., Gomez-Silva, B., Caceres-Villanueva, L., Andersen, D.T. \& Landheim, R. (2003). Temperature and moisture conditions for life in the extreme arid region of the Atacama Desert: four years of observations including the El Nino of 1997-1998. Astrobiology 3 (2), 393-406. 
Meeßen, J., Sánchez, F.J., Brandt, A., Balzer, E.M., de la Torre, R., Sancho, L.G., de Vera, J.P. \& Ott, S. (2013). Extremotolerance and resistance of lichens: comparative studies on five species used in astrobiological research I. Morphological and anatomical characteristics. Orig. Life Evol. Biosph. 43(3), 283-303.

Meeßen, J., Sánchez, F.J., Sadowsky, A., de la Torre, R., Ott, S. \& de Vera, J.-P. (2014). Extremotolerance and resistance of lichens: comparative studies on five species used in astrobiological research II. Secondary lichen compounds. Orig. Life. Evol. Biosph. 43(4), 501-526.

Meredith, P. \& Riesz, J. (2004). Radiative relaxation quantum yields for synthetic eumelanin. Photochem. Photobiol 79(2), 211-216.

Ming, D.W. et al. (2014). Volatile and organic compositions of sedimentary rocks in Yellowknife Bay, Gale crater, Mars. Science 343(6169), 1245267. doi: $10.1126 /$ science. 1245267

Möhlmann, D.T. (2004). Water in the upper Martian surface at mid-and low-latitudes: presence, state, and consequences. Icarus 168(2), 318-323.

Möhlmann, D.T. (2008). The influence of van der Waals forces on the state of water in the shallow subsurface of Mars. Icarus 195(1), 131-139.

Möhlmann, D.T. (2010). The three types of liquid water in the surface of present Mars. Int. J. Astrobiol. 9(1), 45-49.

Murphy, J.R., Leovy, C.B. \& Tillman, J.E. (1990). Observations of Martian surface winds at the Viking Lander 1 site. J. Geophys. Res. 95(B09), 14555 14576.

Nybakken, L., Solhaug, K.A., Bilger, W. \& Gauslaa, Y. (2004). The lichens Xanthoriaelegans and Cetrariaislandica maintain a high protection against UV-B radiation in Arctic habitats. Oecologia 140, 211-216.

Onofri, S. et al. (2012). Survival of rock-colonizing organisms after 1.5 years in outer space. Astrobiology 12(5), 508-516.

Øvstedal, D.O. \& Lewis Smith, R.I. (2001). Lichens of Antarctica and South Georgia. A Guide to their Identification and Ecology, pp. 66-365. Cambridge University Press, Cambridge.

Poulet, F., Bibring, J.-P., Mustard, J.F., Gendrine, A., Mangold, N., Langevin, Y., Arvidson, R.E., Gondet, B., Gomez, C. \& The OMEGA Tедм (2005). Phyllosilicates on Mars and implications for early martian climate. Nature 438, 623-627.

Raggio, J., Pintado, A., Ascaso, C., de la Torre, R., de los Ríos, A., Wierzchos, J., Horneck, G. \& Sancho, L.G. (2011). Whole lichen thalli survive exposure to space conditions: results of lithopanspermia experiment with Aspicilia fruticulosa. Astrobiology 11(4), 281-292.

Rennó, N.O. et al. (2009). Possible physical and thermodynamical evidence for liquid water at the Phoenix landing site. J. Geophys. Res. 114(E1), 1991-2012.

Ried, A. (1960). Thallusbau und Assimilationshaushalt von Laub- und Krustenflechten. BiolZbl 79, 129-134.

Sánchez, F.J., Mateo-Martí, E., Raggio, J., Meeßen, J., Martínez-Frías, J., Sancho, L.G., Ott, S. \& de la Torre, R. (2012). The resistance of the lichen Circinariagyrosa (nom. provis.) towards simulated Mars conditions-a model test for the survival capacity of a eukaryotic extremophile. Planet Space Sci. 72(1), 102-110.

Sánchez, F.J., Meeßen, J., Ruiz, M., Sancho, L.G., Ott, S., Vílchez, C., Horneck, G., Sadowsky, A. \& de la Torre, R. (2014). UV-C tolerance of symbiotic Trebouxia sp. in the space-tested lichen species Rhizocarpongeographicum and Circinariagyrosa: role of the hydration state and cortex/screening substances. Int. J. Astrobiol. 13(1), 1-18.

Sancho, L.G., Schroeter, B. \& del Prado, R. (2000). Ecophysiology and morphology of the globular erratic lichen Aspiciliafruticulosa (Eversm.) Flag.from Central Spain. BiblLichenologica 75, 137-147.

Sancho, L.G., de la Torre, R., Horneck, G., Ascaso, C., de los Ríos, A., Pintado, A., Wierzchos, J. \& Schuster, M. (2007). Lichens survive in space: results from 2005 LICHENS experiment. Astrobiology 7(3), 443-454.

Scalzi, G., Selbmann, L., Zucconi, L., Rabbow, E., Horneck, G., Albertano, P. \& Onofri, S. (2012). The LIFE Experiment: isolation of cryptoendolithic organisms from Antarctic colonized sandstone exposed to space and simulated Mars conditions on the International Space Station. Orig. Life Evol. Biosph. 42, 253-262.

Schultze, D. (1971). Differentialthermoanalyse, Deutscher Verlag der Wissenschaften, 2nd edn, p. 27. Berlin.

Sigfridsson, B. \& Oquist, G. (1980). Preferential distribution of excitation energy into photosystem I of desiccated samples of the lichen Cladoniaimpexa and the isolated lichen-alga Trebouxiapyriformis. Physiol. Plant 49(4), 329-335.

Smith, D.C. (1962). The biology of lichen thalli. Biol. Rev. 37, 537-542.

Smith, P.H. et al. (2009). $\mathrm{H}_{2} \mathrm{O}$ at the phoenix landing site. Science 325(5936), 58-61.

Sohrabi, M. (2012). Taxonomy and phylogeny of the manna lichens and allied species (Megasporaceae). PhD Thesis, Publications in Botany from the University of Helsinki. http://urn.fi/URN:ISBN:978-952-10-7400-4

Sun, H.J., Nienow, J.A. \& McKay, C.P. (2010). The antarctic cryptoendolithic microbial ecosystem. In Life in Antarctic Deserts and other Cold Dry Environments-Astrobiological Analogs, ed. Doran, P.T., Lyons, W.B. \& McKnight, D.M., pp. 110-138. Cambridge University Press, Cambridge.

Tillman, J.E. (1988). Mars global atmospheric oscillations: annually synchronized, transient normal-mode oscillations and the triggering of global dust storms. J. Geophys. Res. 93(D8), 9433-9451.

Valladares, F., Wierzchos, J. \& Ascaso, C. (1993). Porosimetric study of the lichen family Umbilicariaceae: anatomical interpretation and implications for water storage capacity of the thallus. Am. J. Bot. 80, 263-272.

Vaniman, D.T. et al. (2014). Mineralogy of a mudstone at Yellowknife Bay, Gale Crater, Mars. Science 343(6169), 1243480. doi: 10.1126/ science. 1243480

Williams, R.M.E. et al. (2013). Martian fluvial conglomerates at Gale Crater. Science 340(6136), 1068-1072. 